\title{
Modeling of sensitive element for pressure sensor based on bipolar piezotransistor
}

Mikhail Basov ( $\nabla$ engineerbasovm@gmail.com )

Dukhov Automatics Research Institute (VNIIA) https://orcid.org/0000-0003-0798-4500

Denis Prigodskiy

Dukhov Automatics Research Institute (VNIIA)

\section{Research Article}

Keywords: sensitive element, pressure, piezoresistive effect, anisotropy of mobility, on-chip differential ampli-fier, piezotransistor, piezoresistor, finite element method

Posted Date: July 2nd, 2021

DOl: https://doi.org/10.21203/rs.3.rs-677127/v1

License: (1) This work is licensed under a Creative Commons Attribution 4.0 International License. Read Full License 


\section{MODELING OF SENSITIVE ELEMENT FOR PRESSURE SENSOR BASED ON BIPOLAR PIEZOTRANSISTOR}

\section{M.V. Basov, D.M. Prigodskiy}

Abstract: The paper describes modeling of high-sensitivity MEMS pressure sensor based on a circuit containing both active and passive stress-sensitive elements: a differential amplifier utilizing two n-p-n transistors and four p-type piezoresistors. The analysis on the basis of the developed mathematical model for a pressure sensor with traditional piezoresistive Wheatstone bridge and theoretical conclusions regarding the change in the electrical parameters of a bipolar transistor under the influence of deformation was carried out.

Keywords: sensitive element, pressure, piezoresistive effect, anisotropy of mobility, on-chip differential amplifier, piezotransistor, piezoresistor, finite element method

\section{Introduction}

Continuously growing demand for semiconductor pressure transducers (PT) leads to the development of new types silicon integrated pressure sensitive elements (die made in the form of MEMS) with piezoresistive Wheatstone bridge (PSWB, Fig. 1a) [1]. Criteria for functioning of MEMS determine the scope of application for these developments. Actual direction of research in the field of parametric capabilities for MEMS is the problem associated with increasing the output sensitivity of element. There are known the development of die's TD [2-6], in which achievement of required value for strain sensitivity was obtained due to change in geometric structure membrane: the number of rigid islands (RI) and changed area's RI, membrane area increased or membrane thickness decreased. These changes lead to negative factors that are associated with increase in overall die's dimensions or decrease in threshold value of fracture pressure for silicon membrane. The development of a PT pressure sensor with the differential amplifier (PSDA, Fig. 1b), where both p-type passive elements and active npn-type bipolar piezotransistors (BPT) are sensitive to pressure. PSDA is essential to increase sensitivity with respect to analogues PSWB.

\section{Modeling of PSWB}

Let's construct a mathematical model of PSWB for sensitivity calculation and compare the results with measurements of serial samples (110 samples of PSWB were used). In the future we use a verified mathematical model to disclose the principles of functioning die's PSDA. 


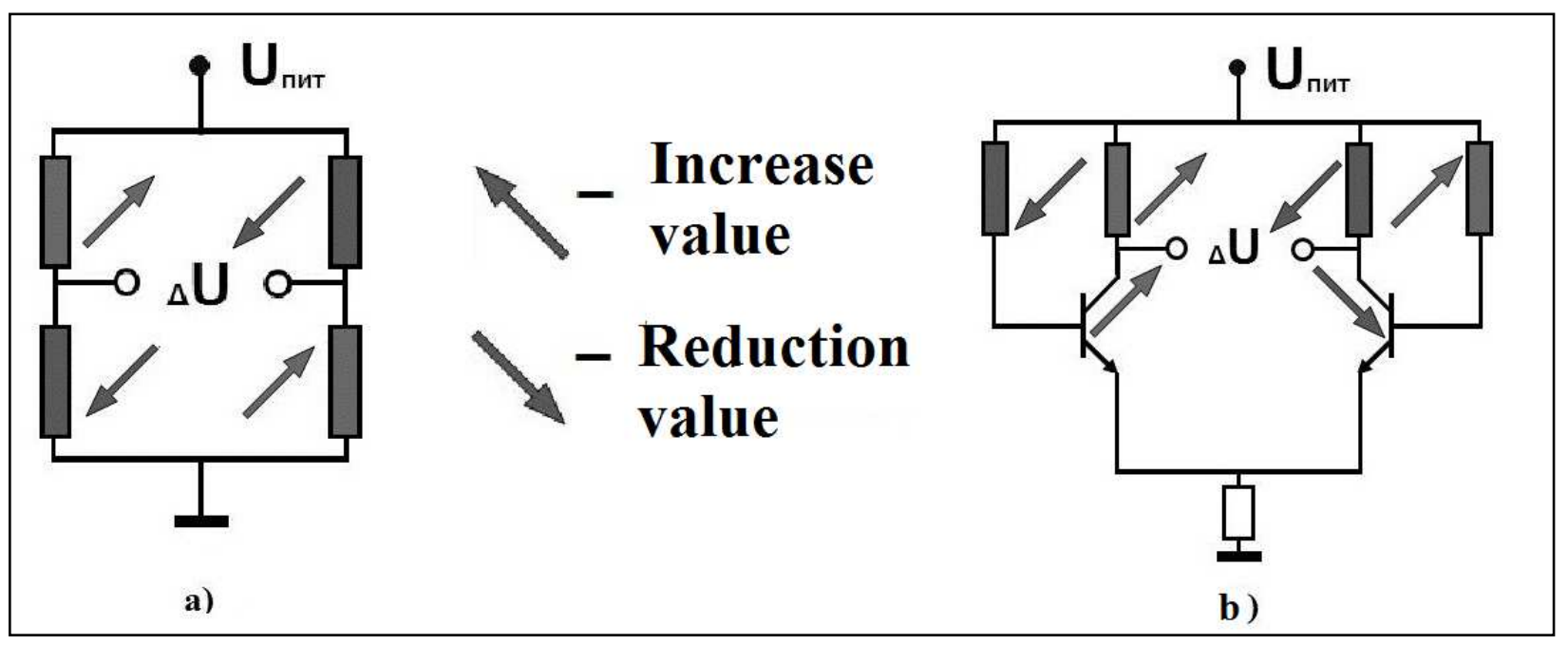

Fig. 1. Electrical circuits of pressure sensor: a) PSWB, b) PSDA

A comparative analysis of die with different types of strain gauges (PSWB and PSDA) will be carried out under the condition of using same membrane geometry (Figure 2, the dimensions are shown in Table 1).

The theory of the piezoresestive effect establishes relationship between the change in the electrical resistance of semiconductor region and mechanical stress in silicon structure by deformation.

Calculation of change resistance by the supply of pressure was carried out using mechanical stresses formed on surface of membrane in regions of piezoresistor (PR) location. This is due to the fact of main charge in PR, which carried out with diffusion or ion implantation doping, occurs to near surface. In the case PR has shape of rectangle with a width of $20 \mu \mathrm{m}$ and a length of $400 \mu \mathrm{m}$. Averaged values of stresses over PR area were used in the calculations.

Mechanical stresses in silicon are considered with applying pressure $\Delta \mathrm{P}=100 \mathrm{kPa}$ from the side of membrane for three kinds of thin part elastic element (Figure 2 and Table 1). Membrane's thickness has variable value W for further comparative analysis with respect to serial samples $(\mathrm{W}=33,42,63 \mu \mathrm{m})$.

Two PR for electrical circuits PSWB are located in zone of maximum compression, i.e. between the thickened region of the membrane (frame) and the RI. Their resistance increases with the supply of pressure. Two PR are located in the zone of maximum extension, i.e. between the two PR. Their resistance decreases with the supply of pressure. When the pressure, change in the output signal of PSWB is applied depends by change resistance PR as follows:

$$
\Delta U=U_{\text {sup }} \frac{\left(R_{1}+\Delta R_{1}\right) \cdot\left(R_{3}+\Delta R_{3}\right)-\left(R_{2}+\Delta R_{2}\right) \cdot\left(R_{4}+\Delta R_{4}\right)}{\left(\left(R_{1}+\Delta R_{1}\right)+\left(R_{4}+\Delta R_{4}\right)\right) \cdot\left(\left(R_{2}+\Delta R_{2}\right)+\left(R_{3}+\Delta R_{3}\right)\right)}
$$




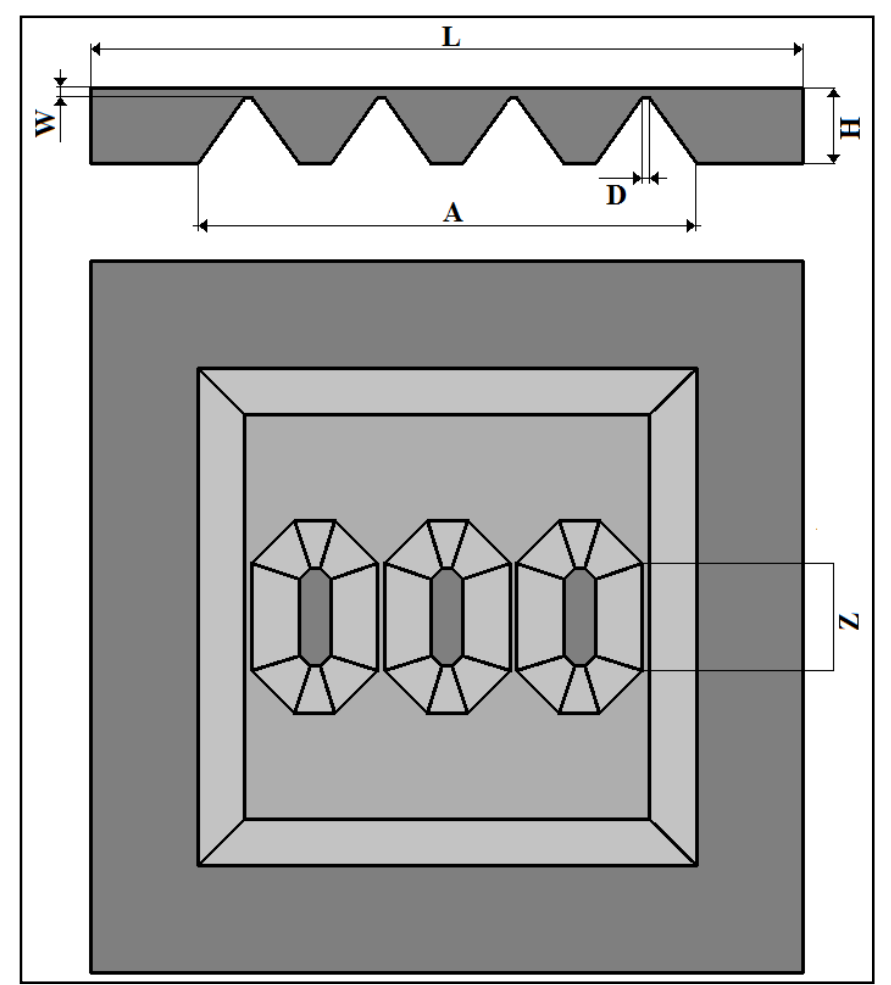

Fig. 2. Geometric structure of membrane

$L$ - length of die's side (die has a square shape),

$W$ - thickness of membrane,

$H$ - thickness of die,

A - length of membrane's side (membrane has a square shape),

$D$ - width of groove between rigid islands or the rigid islands and frame,

$Z$ - length of rigid island's edge.

where $\Delta U$ - changed output signal, $m V ; U_{\text {sup }}$ - supply voltage of circuit, $V ; R_{1,3}$ and $R_{2,4}$ - resistance, located in the zone of compression and expansion of membrane, respectively, Ohm; $\Delta \mathrm{R}_{1,2,3,4}$ - absolute change of resistance, Ohm.

Table 1

Basic geometric parameters of die

\begin{tabular}{|c|c|c|c|}
\hline Samples & 1 & 2 & 3 \\
\hline Parameter & \multicolumn{3}{|c|}{ Dimension, $\mu \mathrm{m}$} \\
\hline L & \multicolumn{3}{|c|}{4000} \\
\hline W & 33 & 42 & 63 \\
\hline H & \multicolumn{3}{|c|}{420} \\
\hline A & \multicolumn{3}{|c|}{2280} \\
\hline D & \multicolumn{3}{|c|}{41} \\
\hline Z & \multicolumn{3}{|c|}{490} \\
\hline
\end{tabular}


The formula for relative change in resistance PR can be written as follows:

$$
\delta=\frac{\Delta R}{R}=\pi_{l} \sigma_{l}+\pi_{t} \sigma_{t}+\pi_{s} \sigma_{s}
$$

where $\pi_{1, \mathrm{t}, \mathrm{s}}$ - longitudinal, transverse and shear piezoresistive coefficients of silicon, respectively, $\mathrm{Pa}^{-1} ; \sigma_{1, \mathrm{t}, \mathrm{s}}$ - longitudinal, transverse and shear mechanical stress in region of PR, respectively, $\mathrm{Pa}$.

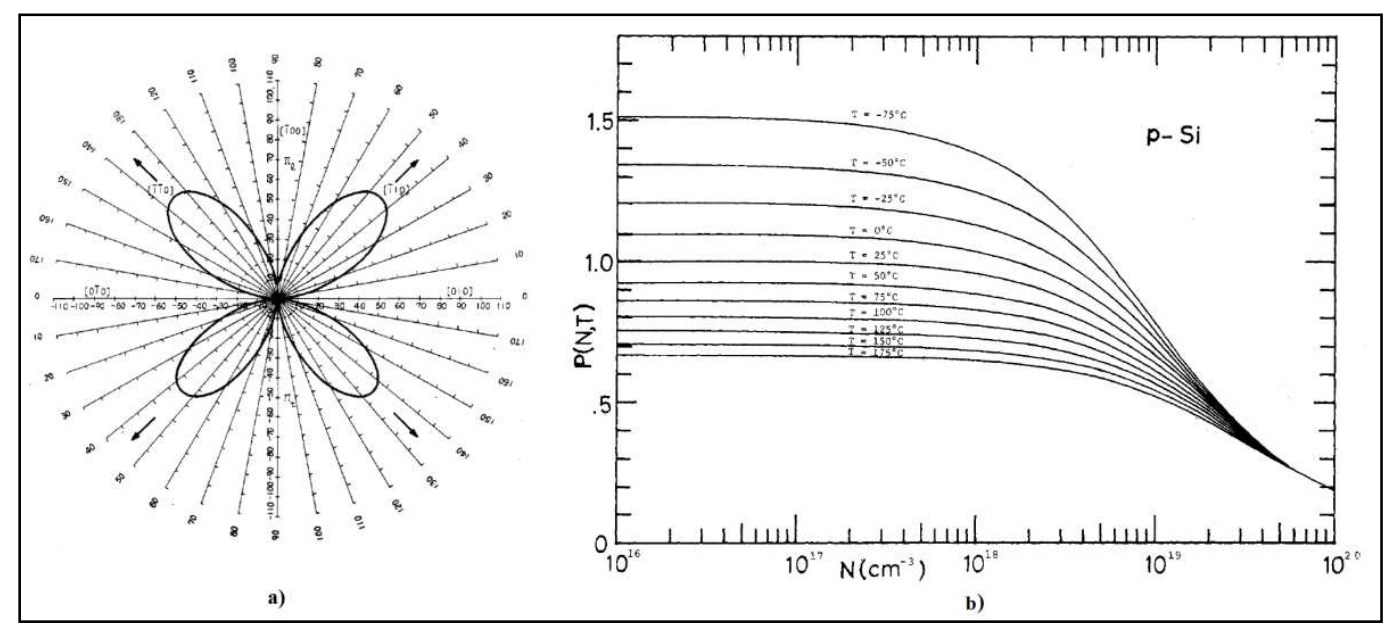

Fig. 3. Dependence of piezoresistive coefficients for p-type silicon: a) in the crystallographic plane (100) at room temperature on crystallographic direction, b) on the concentration and temperature.

The die was made in crystallographic plane (100) and PR is directed in the crystallographic direction [110]. In this case, the shear piezoresistive coefficient $\pi_{\mathrm{s}}$ is equal to zero [7, 8]. In articles [9 - 12] methods for determining the values for $\pi_{1}$ and $\pi_{\mathrm{t}}$ are presented (Fig. 3a). When calculating process, we necessary need to take technological aspects of creating a PR - the method of obtaining doped layers and value of surface impurity concentration $\mathrm{N}_{\mathrm{S}}$ (Fig. 3b). In the case samples have ion doping method with concentration of $3.5 \times 10^{18} \mathrm{~cm}^{-3}$. There is also dependence of the piezoresistive coefficients on temperature, but in this paper we restrict ourselves to analyzing only case at room temperature $\left(\mathrm{T}=25^{\circ} \mathrm{C}\right)$. Following values were obtained for the coefficients $\pi_{1}=-\pi_{\mathrm{t}}=6.12 \cdot 10^{-9}\left(\mathrm{~Pa}^{-1}\right)$. The values of longitudinal $\sigma_{1}$ and transverse $\sigma_{\mathrm{t}}$ mechanical stress are determined by computer simulation and presented in Table 2.

The simulation was carried out by finite element method (ANSYS). Optimization of computer resources involved and accuracy of the final solution was carried out by selecting the parameters of decomposition geometric model for die into finite element (FE) grid. Rectangular cells with size of $50 \mu \mathrm{m}$ were used with local reduction of up to $15 \mu \mathrm{m}$ at locations of the PR. 
This approach allows to reduce calculation time and increase accuracy without increasing the computer resources involved.

Mechanical stresses obtained on PR in compression and expansion zones are actually equal in absolute value and opposite in sign. Example of distribution of mechanical stresses for membrane with thickness $\mathrm{W}=33 \mu \mathrm{m}$ (sample 1) is shown in Fig. 4.

Calculation of sensitivity S of PSWB was carried out according to the formula:

$$
S=\frac{\Delta U_{0}}{U_{\text {sup }} \Delta P}
$$

where $\Delta \mathrm{P}$ - value of apply pressure, $\mathrm{kPa}$.

The values of sensitive are presented in Table 2. Figure 5 shows graphs by dependence of sensitivity $\mathrm{S}$ on the thickness membrane $\mathrm{W}$. The simulation results quite accurately predict the operation of PSWB, i.e. relative change nominal of denomination elements in pressure is applied and output sensitivity.

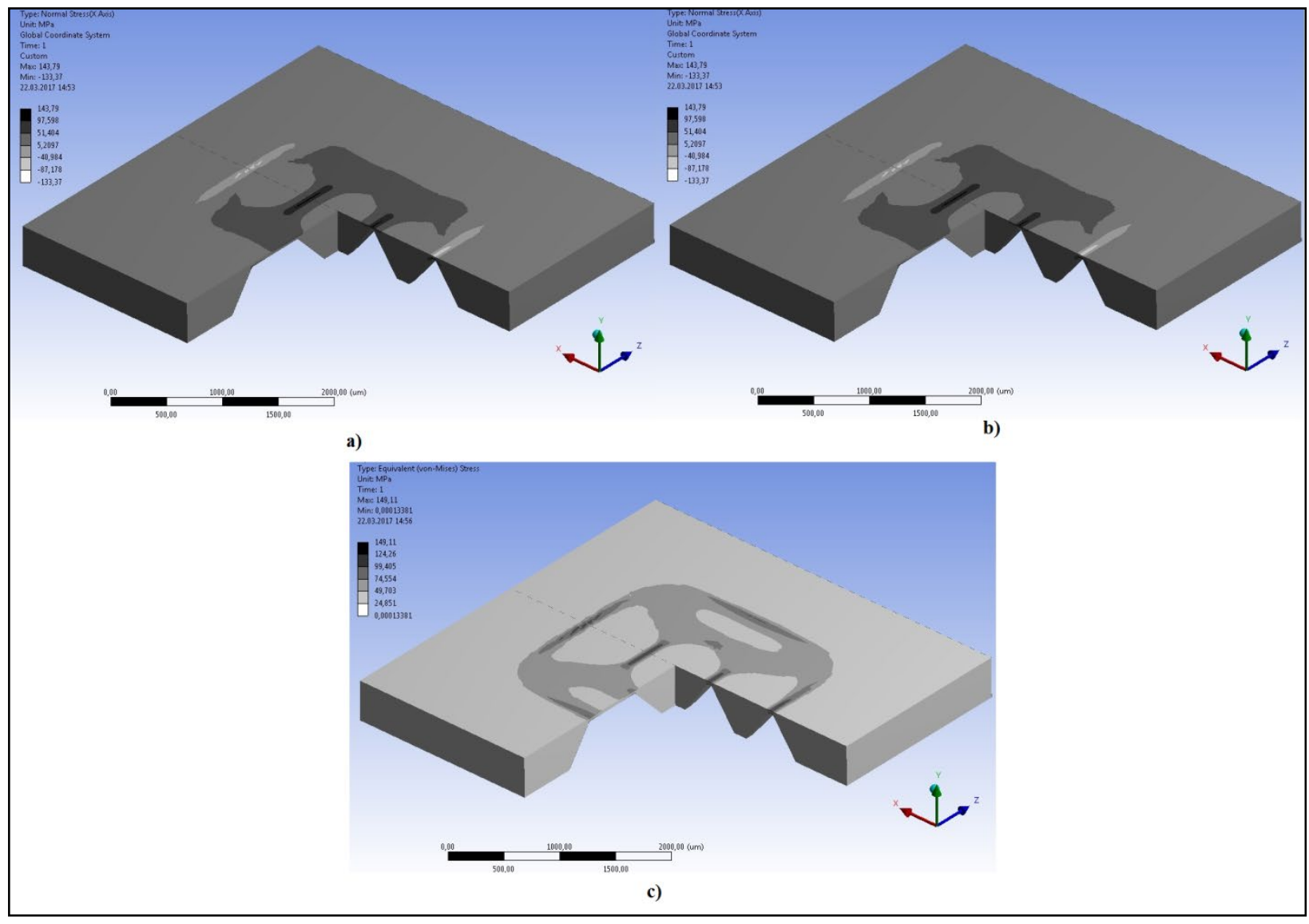

Fig. 4. Distribution of mechanical stresses in die with a membrane thickness $W=33 \mu \mathrm{m}$ : a) in transverse direction relative to the location of $P R, b)$ in longitudinal direction relative to the location of the $P R$, c) by von Mises 


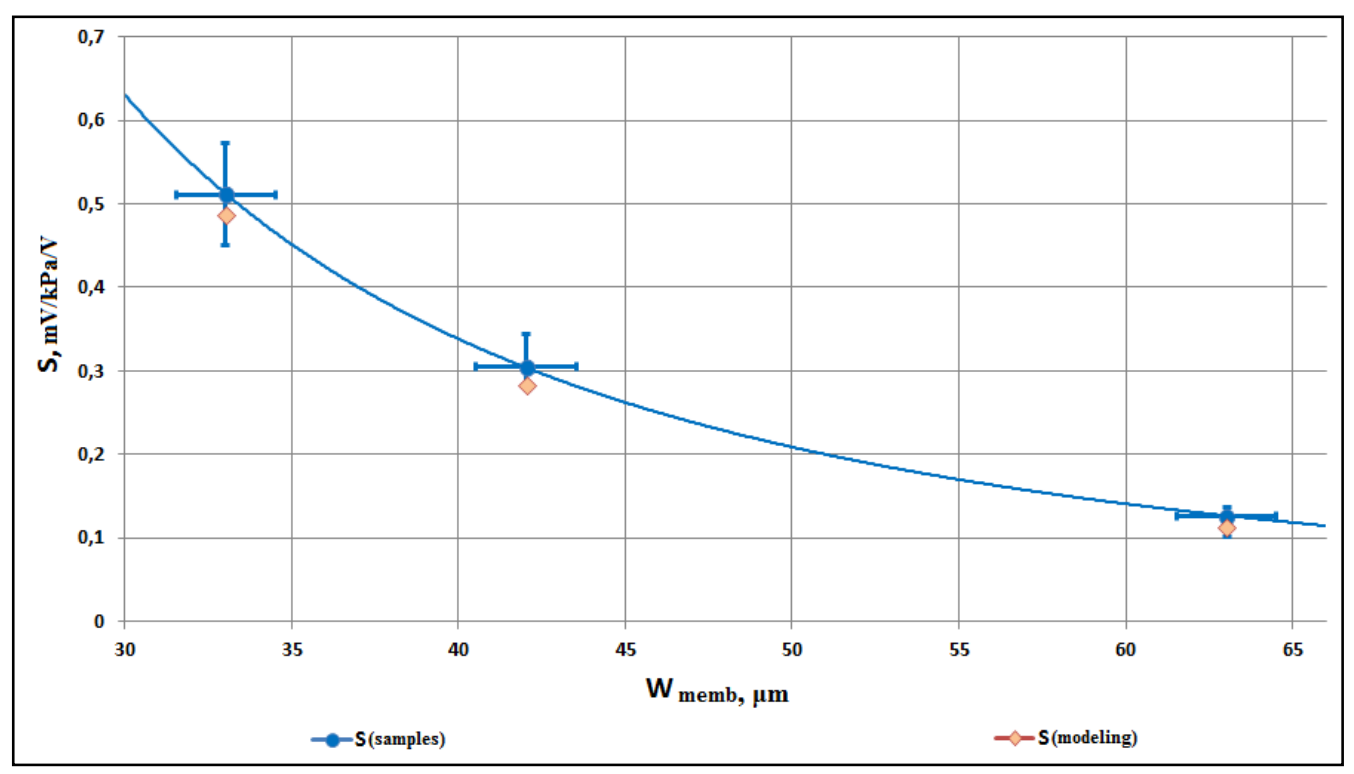

Fig. 5. Comparison of experimental and calculated data for dependence of sensitivity $S$ on the membrane thickness $\mathbf{W}$

The discrepancy between the average values of the sensitivity of serial samples and calculated data is $5-10 \%$. The sensitivity of PSWB depends on geometry membrane, carrier concentration and impurity distribution over the depth of doped layer. Probably this discrepancy is connected with the problem of exact choice these parameters used in modeling. Nevertheless, the received level of discrepancy allows to carry out with high degree of reliability calculation of sensitivity for sensitive pressure elements.

Table 2

Modeled parameters of piezoresistive effect for PSWB

\begin{tabular}{|c|c|c|c|c|c|c|c|c|}
\hline \multirow{2}{*}{\multicolumn{2}{|c|}{$\frac{\text { Parameter }}{\text { Samples }}$}} & \multicolumn{6}{|c|}{ Value } & \multirow{3}{*}{ Dimension } \\
\hline & & 1 & 2 & 3 & 1 & 2 & 3 & \\
\hline \multicolumn{2}{|l|}{ Region of deformation } & \multicolumn{3}{|c|}{ Extension } & \multicolumn{3}{|c|}{ Compression } & \\
\hline \multirow{2}{*}{ Piezoresistive coefficient } & $\pi_{1}$ & \multicolumn{6}{|c|}{$6,12 \cdot 10^{-10}$} & $1 / \mathrm{Pa}$ \\
\hline & $\pi_{\mathrm{t}}$ & \multicolumn{6}{|c|}{$-6,12 \cdot 10^{-10}$} & $1 / \mathrm{Pa}$ \\
\hline \multirow{3}{*}{ Mechanical stress } & $\sigma_{1}$ & 111 & 66 & 27 & -111 & -65 & -26 & $\mathrm{MPa}$ \\
\hline & $\sigma_{\mathrm{t}}$ & 34 & 21 & 8 & -30 & -18 & -7 & $\mathrm{MPa}$ \\
\hline & $\sigma$ & 98 & 58 & 23 & 99 & 59 & 23 & $\mathrm{MPa}$ \\
\hline \multicolumn{2}{|l|}{ Samples } & \multicolumn{2}{|c|}{1} & \multicolumn{2}{|c|}{2} & \multicolumn{2}{|c|}{3} & - \\
\hline Sensitive of PSWB & \multirow{2}{*}{$\mathrm{S}$} & \multicolumn{2}{|c|}{0,487} & \multicolumn{2}{|c|}{0,283} & \multicolumn{2}{|c|}{0,113} & \multirow{2}{*}{$\mathrm{mV} / \mathrm{kPa} / \mathrm{V}$} \\
\hline Sensitive of PSWB (practice) & & \multicolumn{2}{|c|}{0,511} & \multicolumn{2}{|c|}{0,305} & \multicolumn{2}{|c|}{0,126} & \\
\hline
\end{tabular}




\section{Modeling of PSDA}

The above-described mathematical model can be used in the design of work for PSDA. For complement model necessary to disclose the principle of effect pressure on BPT and to obtain theoretical values of relative change parameters of the transistor.

Based on the results of the literature review [13-21] and analysis of experimental sample in the form of single BPT (common emitter circuit) separately located on thin part of elastic element PSWB (Fig. 6). The basis of theory for BPT consisting of two effects:

1. Charge by anisotropy of mobility minority carriers in base region;

2. Piezoresistive effect on base resistance.

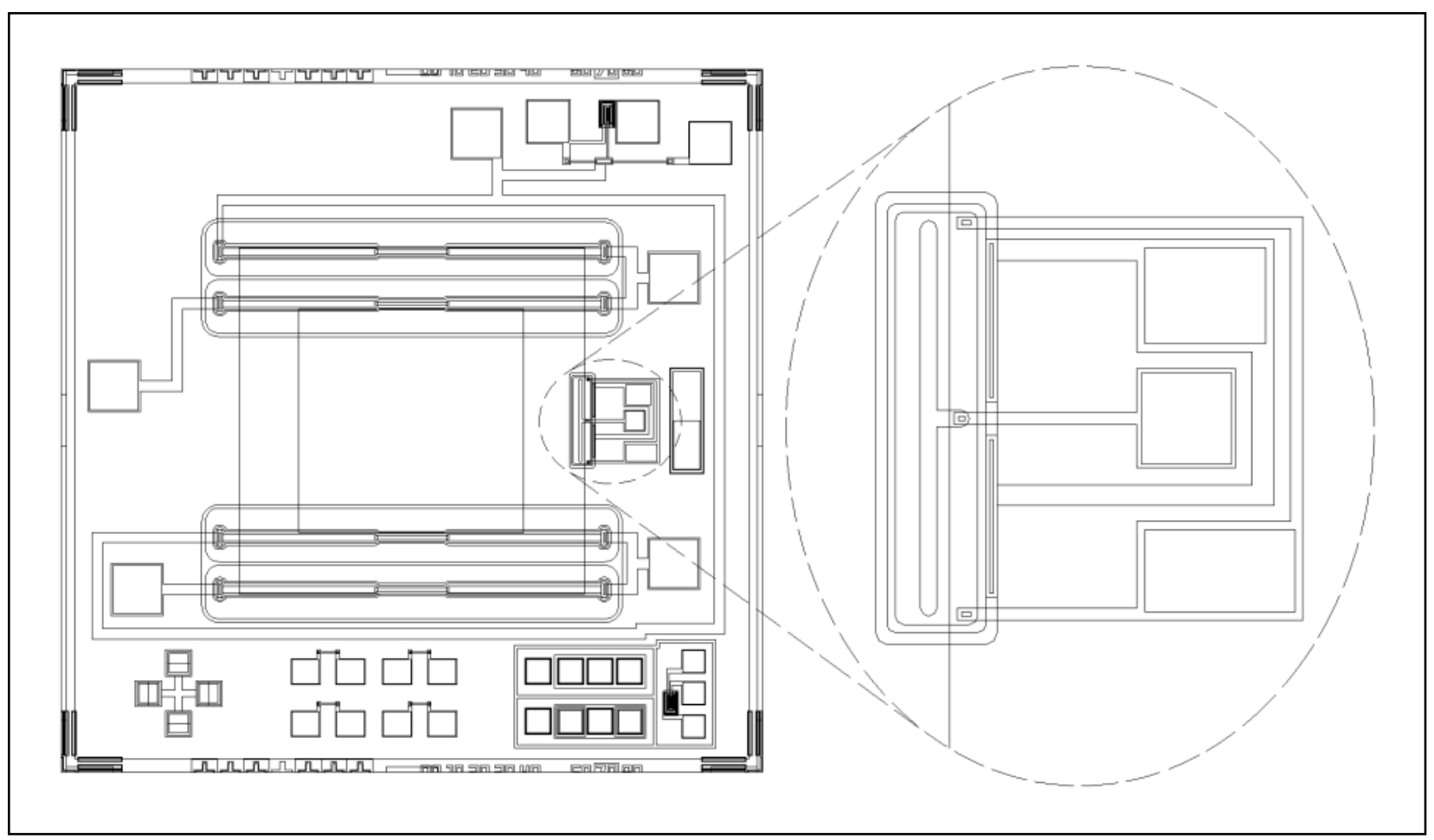

Fig. 6. PSWB with separately formed BPT

The effect of anisotropy mobility minority carriers silicon in the base region BPT (in this case p-type) by deformation is due to the splitting of doubly degenerate energy in the Brillouin valence band at point $\mathrm{k}=0$. First ellipsoids of constant energy shifts upward (along axis with the energy value) and has readings of "light" holes effective mass and the second ellipsoids of constant energy shifts downward with "heavy" holes effective mass. The ratio of values holes mobility by deformation and without deformation can be expressed as follows: 


$$
\frac{\mu_{p}}{\mu_{p 0}}=\frac{m_{l}^{1 / 2}}{m_{l}^{1 / 2}+m_{\mathrm{h}}^{1 / 2}} \cdot \frac{1+\frac{m_{\mathrm{h}}^{1 / 2}}{m_{1}^{1 / 2}} \cdot K^{13 / 2} \exp \left(\frac{\left(\Delta E_{v 1}^{\prime}-\Delta E_{v 2}^{\prime}\right) \cdot \sigma}{k T}\right)}{1+K^{3 / 2} \exp \left(\frac{\left(\Delta E_{v 1}^{\prime}-\Delta E^{\prime}{ }_{v 2}\right) \cdot \sigma}{k T}\right)}
$$

where $\mathrm{m}_{1, \mathrm{~h}}$ - "light" and "heavy" holes effective mass, respectively, $\mathrm{kg}, \mathrm{K}$ ' $=\mathrm{m}_{1} / \mathrm{m}_{2}, \mathrm{~m}_{1,2}$ - effective masses in the minima of conduction band, $\Delta \mathrm{E}_{\mathrm{v} 1}{ }_{\mathrm{V}}-\Delta \mathrm{E}_{\mathrm{v} 2}{ }_{\mathrm{i}}-$ coefficient of splitting top valence band, eV/Pa, $\sigma$ - mechanical stress of region BPT, Pa, k - Boltzmann's constant, eV/K, T - temperature, $\mathrm{K}$. The work of PSDA occurs with small deformations, i.e. in the case $\Delta \mathrm{E}_{\mathrm{G}}<\mathrm{kT}$, where $\Delta \mathrm{E}_{\mathrm{G}}$ is the change in the band gap, eV, and $\mathrm{kT}$ is the thermal energy equal to $25.7 \mathrm{meV}$ at room temperature (when $\Delta \mathrm{E}_{\mathrm{G}}>\mathrm{kT}$, then main contribution to collector current $\Delta \mathrm{I}_{\mathrm{C}}$ is made by change in intrinsic conductivity $\Delta \mathrm{n}_{\mathrm{i}}$ ). Mechanical stresses is value of the von Mises stress with a coefficient of 0.5 [20] for the crystallographic direction [110]. The values of $\mathrm{m}_{1, \mathrm{~h}}$ are tabulated equal to $\mathrm{m}_{\mathrm{l}}=0.12 \cdot \mathrm{m}_{0}=1.093 \cdot 10^{-31} \mathrm{~kg}$ and $\mathrm{m}_{\mathrm{h}}=0.44 \cdot \mathrm{m}_{0}=4.001 \cdot 10^{-31} \mathrm{~kg}$, respectively, where $\mathrm{m}_{0}$ is the mass of free electron $\mathrm{m}_{0}=9.1110^{-31} \mathrm{~kg}$. The effective masses in the minima of conduction band are actually considered to be the same $m_{1}=m_{2}$ under these conditions. The splitting parameter of vertex valence band in the crystallographic plane (100) is also a tabular value, which is the same for simple uniaxial compression and stretching of the silicon structure $\Delta \mathrm{E}_{\mathrm{v} 1}^{\prime}-\Delta \mathrm{E}_{\mathrm{v} 2}=2.38 \cdot 10^{-11}$ $\mathrm{eV} / \mathrm{Pa}$.

The collector current BPT on deformation is:

$$
\frac{I_{\mathrm{K}}}{I_{\mathrm{K} 0}}=\left(\frac{\mu_{p}}{\mu_{p 0}}\right)^{3 / 2} \exp \left(-\frac{\Delta E_{G}^{\prime} \cdot \sigma}{k T}\right)
$$

where $\Delta \mathrm{E}_{\mathrm{G}}$ - the coefficient of change band gap and it is experiment's value $\Delta \mathrm{E}_{\mathrm{G} \text { ext }}=$ $-3,57 \cdot 10^{-11} \mathrm{eV} / \mathrm{Pa}$ and $\Delta \mathrm{E}_{\mathrm{G} \text { comp }}=-7,39 \cdot 10^{-11} \mathrm{eV} / \mathrm{Pa}$. The values of relative change collector current $\delta \mathrm{I}_{\mathrm{K}}$ in absence associated with mobility anisotropy effect are presented in Table 3.

Piezoresistive effect on resistance of base area BPT (p-type) suggests that the value of collector current is inversely proportional to change in resistance value base region $\Delta \mathrm{I}_{\mathrm{C}}$ of the tensor $\sim 1 / \Delta \mathrm{R}_{\mathrm{B}}$. In order to achieve the greatest efficiency BPT in terms of strain sensitivity, it is necessary that the relative change in the collector current according to previously described effect and strain resistance of base region have the same sign. When BPT located in the left branch of the differential amplifier (Fig. 1b), i.e. when pressure is applied from the membrane side, the collector current $\Delta \mathrm{I}_{\mathrm{C}}>0$ increases. BPT necessary to place it between frame and RI (compression zone) in the radial arrangement, since in this case nominal value will decrease in the p-type resistor. Similarly, BPT located in the right branch of the differential amplifier (Fig. 1b), i.e. when 
supplying pressure from the membrane, reduces the collector current $\Delta \mathrm{I}_{\mathrm{C}}<0$. BPT necessary to place it between the two RI (extension zone) in the radial arrangement, since in this case nominal value will increase in the p-type resistor. When the base area BPT located along the tangential direction in the membrane, two effects will have different signs and partially compensate each other. Calculation of change resistance value of base area BPT is carried out by analogy with the method described in the previous section (simulation of PSWB). The difference in the radial and tangential location is the mutual replacement of longitudinal stress by transverse. Transverse voltage has a longitudinal stress. Since length of base area BPT is order of $50 \mu \mathrm{m}$, it can be assumed as values of longitudinal mechanical stress for radial location of base are constant. The values of relative change in collector current $\delta \mathrm{I}_{\mathrm{K}}$ of tensors associated with piezoresistive effect are presented in Table 3. All PR of PSWB and PSDA are located tangentially.

The combination of the two effects gives full value of change collector current $\delta \mathrm{I}_{\mathrm{C}} \mathrm{BPT}$ :

$$
\delta I_{C}=\delta I_{C \text { anis }}+\delta I_{C \text { piez }}
$$

The theoretical results of combination two effects are given in Table 3.

Table 3

Modeled parameters of strain effect PSDA

\begin{tabular}{|c|c|c|c|c|c|c|c|c|}
\hline \multicolumn{2}{|l|}{ Parameter } & \multicolumn{6}{|c|}{ Value } & \multirow{3}{*}{ Dimension } \\
\hline Samples & & 1 & 2 & 3 & 1 & 2 & 3 & \\
\hline \multicolumn{2}{|l|}{ Deformation region } & \multicolumn{3}{|c|}{ Extension } & \multicolumn{3}{|c|}{ Compression } & \\
\hline \multirow{3}{*}{$\begin{array}{l}\text { Relative change of collector } \\
\text { current } \delta \mathrm{I}_{\mathrm{C}}\end{array}$} & $\delta \mathrm{I}_{\mathrm{C} \text { anis }}$ & $-8,3$ & $-4,8$ & $-1,9$ & 16,5 & 9,5 & 3,7 & \multirow{3}{*}{$\%$} \\
\hline & $\delta \mathrm{I}_{\mathrm{C} \text { piez }}$ & $-4,5$ & $-2,7$ & $-1,1$ & 5,2 & 3,0 & 1,2 & \\
\hline & $\delta \mathrm{I}_{\mathrm{C}}$ & $-12,8$ & $-7,5$ & $-3,0$ & 21,7 & 12,4 & 4,8 & \\
\hline
\end{tabular}

\section{RESULTS AND DISCUSSIONS}

We use SPICE simulator in the NI Multisim software for simulating patterns of changes in all strain elements PSWB and PSDA (Fig. 7). The following technological parameters were used in the reproduction BPT: the potential of base-emitter transition field $\mathrm{U}_{\mathrm{BE}}=0.68 \mathrm{mV}$ and the return current of collector junction $\mathrm{I}_{\mathrm{C} \text { rev }}=1 \mathrm{nA}$. Value for all types of strain gauges has supply voltage $\mathrm{U}_{\text {sup }}=5 \mathrm{~V}$. The nominal values of PSDA tensile elements are: collector resistance BPT $\mathrm{R}_{\mathrm{C}}=2.2$ 
$\mathrm{kOhm}$, base resistance $\mathrm{BPT} \mathrm{RB}=5.4 \mathrm{kOhm}$, gain $\mathrm{BPT} \beta=50$. External pressure-insensitive resistor for set the specific current in base of $\mathrm{R}_{1}=120 \mathrm{k} \Omega$.

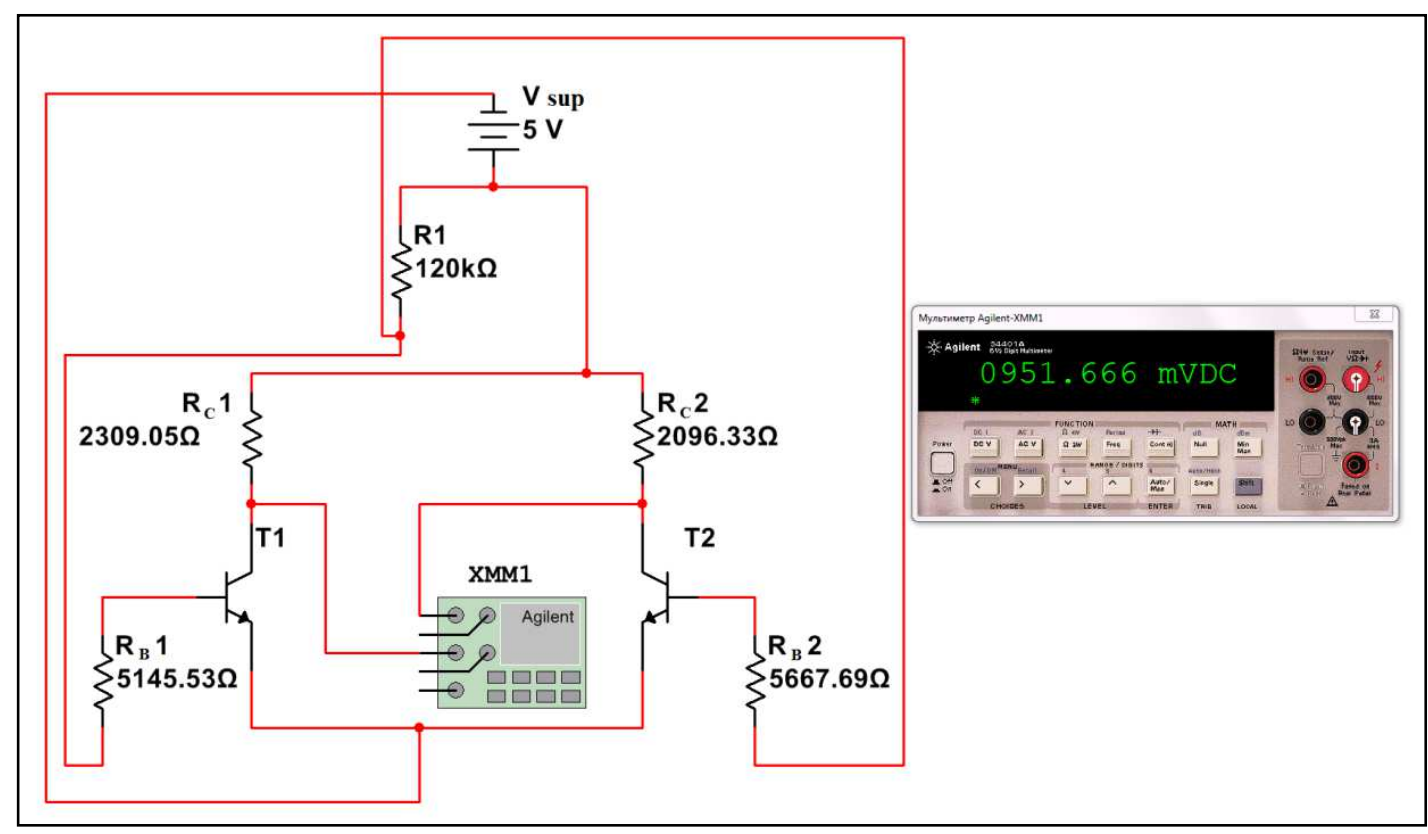

Fig. 7. Modeling of sensitive improved PSDA (sample 1)

The results of calculated output sensitive are shown in Table 4.

Modeled sensitive parameters by SPICE

\begin{tabular}{|c|c|c|c|c|c|}
\hline \multirow{2}{*}{$\begin{array}{c}\text { Die } \\
\text { Samples }\end{array}$} & & \multicolumn{3}{|c|}{ Value } & \multirow{2}{*}{ Dimension } \\
\hline & & 1 & 2 & 3 & \\
\hline PSDA & \multirow{2}{*}{$\mathrm{S}$} & 1,903 & 1,095 & 0,437 & \multirow{2}{*}{$\mathrm{mV} / \mathrm{kPa} / \mathrm{V}$} \\
\hline PSWB & & 0,487 & 0,283 & 0,113 & \\
\hline \multicolumn{2}{|c|}{ Advantage } & 3,91 & 3,87 & 3,88 & - \\
\hline
\end{tabular}

\section{CONCLUSION}

The simulation of PSWB with a membrane having $3 \mathrm{RI}$ is able to predict the results of output sensitivity for pressure transducer with accuracy of $5-10 \%$. In this paper theory of the change collector current BPT by deformation is disclosed. When the BPT position is located along the radial direction of membrane, then anisotropy effects of mobility minority carriers in base region and piezoresistive effect of base region resistivity are added. Based on the results simulation, we can say: using of new type of PSDA, where resistors and bipolar transistors are sensitive to pressure, can increase output sensitivity by 3.9 times relative to PSWB. 
Authors are grateful to Khimushkin Boris Ivanovich for his help in theoretical issues and to Vladimir Yuryevich Fomichev for assistance in the schematic aspects of development.

\section{REFERENCES}

1. Meng X., Zhao $Y$. The design and optimization of a highly sensitive and overload-resistant piezoresistive pressure sensor // MDPI «Sensors». 2016. №16. Pp. 1-12.

2. Zemljannikov N. S., Danilova N. L., Pankov V.V., Suhanov V.S., Mihajlov Ju.A. Tensoresistive pressure transducers based on complex silicon membranes // Nano- i mikrosistemnaja tehnika. 2013. №4. Рp. 32-36.

3. Suhanov V.S., Pankov V.V., Godovicyn I. V., Mihajlov Ju.A., Danilova N. L., Zemljannikov N. S. Strain-resistive integrated MEMS membrane pressure transducer // Nano- i mikrosistemnaja tehnika. 2011. №12. Pp. 36-37.

4. Artemova A. I., Mihajlov Ju.A., Pankov V.V., Suhanov V.S. Optimization of the design of a pressure sensitive element with a distributed rigid center using computer-aided threedimensional modeling // Nano- i mikrosistemnaja tehnika. 2014. №7. Pp. 34-37.

5. Ignateva E.V., Mihajlov Ju.A., Timoshenkov S.P. About the design of a membrane with a rigid center of crystals of silicon strain gauges at a pressure of 0.025 to $25 \mathrm{MPa} / /$ Nano- $\mathrm{i}$ mikrosistemnaya Tekhnika. 2010. No. 2. Pp. 24-31.

6. Belov N. S., L. Lihua, V. Kim, V Dinh. Low pressure sensors and flow sensors // Patent USA. US2015192487 A1. 2016. Pp. 1-30.

7. Vaganov V.I. Integral strain gauges // Moscow. Jenergoatomizdat. 1983. Pp. 15-27.

8. Ageev O.A., Mamikono-va V.M., Petrov V.V., Kotov V.N., Negodenko O.N. Microelectronic converters of non-electrical quantities / Taganrog. Izd-vo TRTU. 2000. Pp. 54-65.

9. Smith C.S. Piezoresistance effect in germanium and silicon / Physical Review. 1954. V. 94. №1. Pp. 42-49.

10. Kanda Y. A Graphical Representation of the Piezoresistance Coefficients in Silicon // IEEE Transactions on electron devices. 1982. Vol. ED-29, № 1. Pp. 64-70.

11. Eaton W.P. Surface micromachined pressure sensors // Dissertation...of doctor of philosophy engineering. Albuquerque. 1997. Pp. 80-96.

12. Doll J.C., Pruitt B.L. Piezoresistor design and application / New York. Springer. 2013. Pp. $22-38$.

13. Babichev G.G., Kozlovskij S.I., Romanov V.A., Sharan N.N. Silicon two-emitter differential strain gage with accelerating electric field in the base // Zhurnal tehnicheskoj fiziki. 1999. T. 69. No. 10. Pp. 63-68. 
14. Neizvestnyj I.G., Gridchin V.P. The use of strained silicon in transistors and CMOS structures // Mikrojelektronika. 2009. №2. Pp. 83-98.

15. Vaganov V.I. Electronic measuring technology. Moscow. Atomizdat. 1978. Pp. 124-130.

16. Vaganov V.I. Microelectronic pressure transducer // Patent USSR. SU1328700 A1. 07.08.1987. Pp. 1-2.

17. Poljakova A.L. On the sensi-tivity of p-n transitions to small deformations // Moscow. Akusticheskij zhurnal. 1967. №2. Pp. 256-261.

18. Poljakova A.L. Physical principles of operation of semiconductor sensors of mechanical quantities // Moscow. Akusticheskij zhurnal. 1972. №1. Pp. 1-22.

19. Poljakova A.L. On the sensitivity to pressure of surface-barrier semiconductor devices // Moscow. Akusticheskij zhurnal. 1974. №3. Pp. 443-448.

20. Poljakova A.L. Deformation of semiconductors and semiconductor devices // Moscow. Jenergija. 1979. Pp. 124-128.

21. Vikulin I.M., Stafeev V.I. Physics of semiconductor devices / Moscow. Radio i svjaz. 1990 г. Pp. 209-218.

Basov Mikhail Viktorovich - engineer Dukhov All-Russian Research Institute of Automatics;

Ph. 84993214929

E-mail:basov.vniia@gmail.com

Prigodskiy Denis Mikhailovich - engineer-researcher Dukhov All-Russian Research Institute of Automatics;

Ph. 84993214929

E-mail:dprigodskyi@gmail.com 